\title{
Lefort para além de Merleau-Ponty
}

Lefort Beyond Merleau-Ponty

\section{Luiz Damon Santos Moutinho Universidade Federal de São Carlos | São Paulo | Brasil}

\section{RESUMO}

$\mathrm{O}$ artigo sustenta que uma alternativa fecunda de leitura da obra de Lefort é tomá-la a partir de uma oposição entre filosofia da história e filosofia política. Pois, aparentemente, a filosofia política madura de Lefort só se constitui a partir do momento em que ele se liberta da possibilidade da filosofia da história.

\section{PALAVRAS-CHAVE}

Claude Lefort; Filosofia; História; Política.

\begin{abstract}
The article maintains that a fertile alternative of reading of the work of Lefort is taking it from an opposition between philosophy of history and political philosophy. Because apparently, the mature political philosophy of Lefort is constituted only from the moment in which it is freed from the possibility of the philosophy of history.
\end{abstract}

\section{KEY WORDS}

Claude Lefort; Philosophy; History; Politics. 
Parece-me que uma alternativa fecunda de leitura da obra de Lefort é tomá-la a partir de uma oposição entre filosofia da história e filosofia política. Aparentemente, a filosofia política madura de Lefort só se constitui a partir do momento em que ele se liberta da possibilidade da filosofia da história.

Façamos aqui um rápido percurso dessa obra. Lefort começa, nos anos 50 , questionando a ideia de História Universal, e o confronto é ali voltado contra Hegel, Marx e, em certa medida, também contra Husserl. O ponto destacado por Lefort é o papel negativo atribuído às "sociedades 'sem história”, "primitivas" etc. Naquela ocasião, ele recorre à Antropologia Política, buscando formas de historicidade próprias, autônomas; a diversidade que daí resulta põe em xeque a lei única da História.

Mas esse começo é ambíguo. Lefort se apoia ainda em Hegel, via Kojève como era de praxe, para traçar objeçôes à antropologia de Lévi-Strauss. Ele recorre à ideia de luta pelo reconhecimento e ainda verá no trabalho o elemento

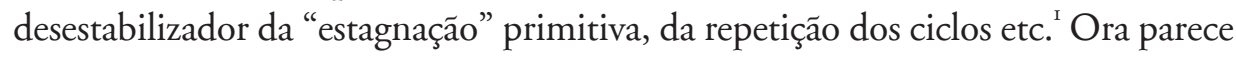
deslocar a centralidade do "modo de produção", ora vê nele a chave para explicar a passagem do modo primitivo a outro.

Esses textos iniciais são erráticos, tateantes. Mas já é visível a presença forte de Merleau-Ponty. O debate com Lévi-Strauss, por exemplo, é muito próximo daquele que o próprio Merleau-Ponty fará pouco tempo depois, no momento em que rejeita o primado da estrutura. O que está em questão para Lefort nesse momento? Aquilo que será sempre o seu problema, a sua marca própria: a busca dos "princípios geradores do social", a "forma" do social, ou da "instituição do social". São expressões que ocorrem no começo e no fim de sua carreira (veja-se, por exemplo, "A questão da democracia" $)$, como também foi a questão da fase intermediária, a maquiaveliana: Maquiavel não será para Lefort o pensador do realismo político, da razão de Estado etc., mas o pensador da fundação do Estado, da "fundação incessante".

Ora, nessa fase inicial, independentemente da resposta, da variedade de respostas a essa questão fundamental, do caráter tateante e errático, já aparece ali um elemento que vai colocar sérios problemas logo adiante: é que essa fundação, apesar de pequenas variações nas respostas, terá sempre a práxis social como seu ponto de fuga. Não é um equívoco fazer como Poltier e denominar esse período como o de uma "fenomenologia do social".

I Ver "A troca e a luta dos homens", uma mistura de antropologia - e seu conceito nuclear - e hegelianismo kojèviano, com centralidade no reconhecimento como fonte da antropogênese, em LEFORT, Claude, Les formes de l'histoire. Essais d'anthropologie politique, Paris: Gallimard, 1978.

2 Lefort, Claude. Essais sur le politique. XIXe-XXe Siècles, Paris : Éditions du Seuil, 1986. 
Mas não tarda muito e uma primeira grande inflexão se faz notar, e ela está ligada a uma virada do próprio Merleau-Ponty. É o momento em que Merleau-Ponty experimenta a necessidade de passar à história, depois de sua fenomenologia da percepção. Ora, essa passagem é já uma autocrítica. Merleau-Ponty vai pensar sua "filosofia da história" a partir dos estudos sobre linguagem. Ele crê que o modelo da linguagem oferece uma alternativa aos modelos hegeliano e marxista e os submete àquele tratamento tão recorrente nele: ambos implicam em "sobrevoo", ou bem objetivismo ou bem subjetivismo - o que resulta, por exemplo, em um marxismo "dedutivista", até mesmo "terrorista", que anula a particularidade. A linguagem oferece uma alternativa válida a essas aporias.

No que nos concerne aqui, é o momento em que, profético, Merleau-Ponty sugere a volta a Maquiavel. Mas por que Maquiavel? Porque ele já começa a desembarcar daquela canoa que vê no proletariado a encarnação do universal: a experiência soviética, àquela altura, já desautorizava a hipótese de uma "solução", o "poder revolucionário" já se revelava "autonomizado", constituindo, assim, uma "camada dirigente" e "sem controle". ${ }^{3}$ É preciso questionar o poder - e nessa perspectiva: o poder "em situação", no seu "movimento vital”, em sua "verdade efetiva" e não imaginária, passagens que Lefort replica a partir de citações do próprio Maquiavel, e que sugere, tanto a Merleau-Ponty quanto a Lefort, uma aproximação com o pensador florentino.

Grosso modo, o projeto de trabalho que se anuncia para o jovem Lefort é: I) pensar o político por ele mesmo, não só, como faz Maquiavel, sem referência à teologia e à cosmologia, mas ainda (e aqui reside a autocrítica, uma superação da "fenomenologia do social") sem referência ao social: o poder não será projeção de relações sociais; daí o primado do político; 2) pensar outra noção de conflito: sem "solução" para o "problema social". Desaparecem a arkhê e o telos. E o proletariado deixa de encarnar o universal.

Do lado de Lefort, o que traz a leitura de Maquiavel? Penso que ela prepara aquela função simbólica que será essencial a sua filosofia política madura. O corpo do príncipe, para além da imagem que dele fazem dominantes e dominados, os grandes e o povo, isto é, os súditos, confere uma unidade à sociedade dividida. É apenas nesse momento que a força se converte propriamente em poder político, essencial à unidade do reino. Esse modelo, em que o poder se corporifica (corpo real e corpo simbólico), será essencial ao contraponto com o poder democrático.

Do lado de Merleau-Ponty, o que traz a nova filosofia da história? Uma noção chave, a reversibilidade, que permite a Merleau-Ponty escapar às aporias dos modelos universalistas, e que no fundo remetem todas, uma vez levadas ao

3 Ver "Nota sobre Maquiavel”, In Merleau-Ponty, I96o. 
seu limite, à ontologia moderna do sujeito e do objeto. A reversibilidade tocante / tocado, corpo / mundo oferece a alternativa de escapar a uma síntese localizada: na Fenomenologia da percepção, a síntese passa pelo corpo, ainda que ele não seja o autor dela. Lefort entende, a partir daí, que o corpo é solidário ao projeto de restituir o fundo que a metafísica obscurece e, portanto, de igualar o Ser e o pensamento e totalizar o "objeto". Esse "fazer a síntese" é o que permite pensar um fato histórico — o proletariado — capaz de realizar o universal, isto é, de pensar a história como curso único.

É essa possibilidade que desaparece na nova filosofia da história de Merleau-Ponty. Por quê? A reversibilidade é pensada a partir da carne, não mais do corpo, e a carne não é resultado de uma sintese. O corpo, menos que o lugar onde passa a síntese, será um desvio (écart) em relação a essa totalidade que é a carne, tanto quanto o signo linguístico é desvio em relação à totalidade que é a língua. Resiste aqui, portanto, a totalidade, mas não mais como totalização em curso. Vem daí que a história se abra para um verdadeiro éclatement, para uma multiplicidade que ela agora pode comportar porque não é mais pensada do ponto de vista do corpo. Para Lefort, não resta mais a possibilidade daquela identidade entre Ser e pensamento, e a história pode então se abrir à indeterminação, essencial a Lefort para pensar a sociedade democrática.

Do lado de Lefort, por que essa solução ainda não é satisfatória? Penso que o essencial está no desdobramento daquilo que o seu Maquiavel já lhe ensinava: a descoberta daquela dimensão simbólica que ele vai explorar intensamente nos anos seguintes para pensar as diversas formas sociais ("primitiva", feudal, moderna, democrática, totalitária). Para ir diretamente ao ponto: a carne merleau-pontiana é o elemento comum, aquilo que me vincula ao mundo e a outros corpos, aquilo que tudo vincula. Ora, é esse "comum" que Lefort não pode admitir. Como se, entre mim e a coisa, não houvesse um terceiro elemento, aquele que, no limite, prepara o acesso à coisa. Esse terceiro termo não é pensável a partir da reversibilidade entre mim e a coisa, ele é irredutivelmente Outro. Se Merleau-Ponty pode repetir que vemos o mundo como no primeiro dia, é porque a carne é esse elemento, essa "eternidade". Para Lefort, ao contrário, há um terceiro elemento, essa Alteridade que não pode ser "social", "empírica", "natural", "fato histórico". Dito de outro modo: o princípio gerador do social, seu antigo problema, não pode ser mais de ordem social, ele antes prepara o espaço social, e por isso não pode estar nele. $\mathrm{O}$ "lugar vazio" é esse terceiro termo da forma democrática.

É a exacerbação da crítica do totalitarismo que previne Lefort da ideia de que a sociedade política seja una consigo mesma na pura imanência - quer dizer, da ideia de que uma parte qualquer do social (uma classe, um grupo) possa visar essa totalidade, encarnar a totalidade, realizar a totalidade. Nem mesmo os 
discursos terão esse condão de colocar-se em uma tal perspectiva totalizante, esse pensamento de sobrevoo que não seria, ele, situado em parte alguma. A lógica totalitária começa aí: pela identificação entre o partido e o social, entre os dirigentes e o partido, entre o Egocrata e os dirigentes. Lei, poder e saber convergem todos para esse único ponto que atravessa a totalidade do social. A recusa do totalitarismo vai se converter então na recusa de que qualquer fato social possa encarnar, portar a universalidade.

Mas não são apenas os acontecimentos políticos que precipitam Lefort nessa recusa. Ela é também de ordem especulativa. O prestígio do simbólico, na medida em que ele ultrapassa o nível das relaçōes puramente sociais, vai se firmando como uma Alteridade radicalmente constitutiva de toda a experiência humana, já atestada pela experiência do infante. Ali onde Merleau-Ponty vê "simetria" e reversibilidade entre os sujeitos, todos vinculados a uma única carne, Lefort vê antes o sujeito iniciado no mundo por um Outro: para além da relação fusional com a mãe, o infante é confrontado com a mediação de um terceiro, que opõe a Lei a seu desejo. Há uma mediação análoga a essa que institui o social. ${ }^{4}$ Quer dizer, o social não repousa apenas sobre si mesmo, essa instituição não é um "fato social" - ou, como diz Lefort, a democracia não possui o sentido de sua própria gênese, a humanidade se vê tomada em uma abertura que ela não faz. Assim, é a eficácia simbólica que funda a sociedade política, não o contrato, não acordo real ou hipotético.

Ora, várias serão as formas sociais, vários serão os simbólicos (das sociedades "primitivas", feudais, modernas, democráticas) e, o que me parece importante assinalar, o simbólico não comporta história. A sociedade democrática, por exemplo, é a sociedade histórica por excelência, porque aberta à indeterminação, mas a história se passa no nível intra-social, não no nível do simbólico. Não há passagem de um simbólico a outro, isto é, não há razão da passagem. A gênese da democracia é contingente. Desprestígio total da filosofia da história.

É só então que Lefort pode constituir a sua "filosofia política", pois esse simbólico, isso que institui o espaço social é político: irredutibilidade do político frente a qualquer dimensão do social. Fixemo-nos um pouco na sociedade democrática.

O que é inédito na democracia é que, enquanto nas sociedades pré-modernas o corpo do rei agia como mediador entre o visível e o invisível, esse Outro mundo, na democracia não há mais figura de mediação; é isso que Lefort chama a "desincorporação do poder"; permanece o lugar do Outro, mas ele permanece como um lugar vazio.

4 Ver "Flesh and Otherness", In Ontology and Alterity in Merleau-Ponty. Evanston: Northwestern University Press, I990. 
Daí porque a sociedade democrática será por excelência a sociedade da indeterminação, aquela que não fixa marcos de certeza, aquela aberta à invenção.

"Lugar vazio" não é estrutura, não é passível de formalização. Não é forma, como na filosofia transcendental. Não é o Ser heideggeriano, distinto dos entes, pois ele não faz nenhum chamado. Ele consagra um modo interrogativo do social. Nisso, permanece merleau-pontiano. Onde está a diferença com Merleau-Ponty? Merleau-Ponty crê na eternidade, "eternidade existencial", na permanência da "carne": vemos o mundo como no primeiro dia. (Não que, agora como antes, vejamos todo o mundo, ainda assim é o mesmo mundo, igual e diferente.) Em suma, Merleau-Ponty crê na história - claro que, do mundo, da natureza, à história, há um passo, mas lá, como aqui, há permanência. Lefort rompe com a história. Ele dá um salto para fora da história. Quer dizer, um salto para fora do que agora lhe aparece como um plano puramente social. A história preserva esse compromisso: Merleau-Ponty não conserva mais a ideia de curso único, certamente (essa ideia guarda compromissos demais, preserva o universal), mas, se não conserva o curso único, conserva ainda a história, agora entendida a partir da ideia de reversibilidade: esta é um meio para afirmar, a um só tempo, a pluralidade e assegurar que essa pluralidade se mantenha coesa, unidas pela carne única. É por isso que Merleau-Ponty vai permanecer "relativista" (por causa da pluralidade), sem poder admitir clivagem entre democracia e totalitarismo. Lefort, por sua vez, vai guardar uma medida, algo como um direito natural às avessas: não valora, não diz o que é o justo, mas impede, de modo absoluto, que o direito se cristalize; de modo radical, legítimo é o debate sobre o legítimo e o ilegítimo. Daí o radical juízo contra o totalitarismo. Lefort não é relativista; há um absoluto ali, mas que é dissolvente: é isso o lugar vazio. Daí o grande interesse pela filosofia política, que só se ergue sobre os escombros da filosofia da história. Não à toa os atuais leitores de Merleau-Ponty na França preferem o lado "natureza" do que o lado "história" dessa carne. É como se, às cegas, tivessem se dado conta da insuficiência da filosofia da história de Merleau-Ponty, mas então eles deveriam, de algum modo, se posicionar diante de Lefort, o que, definitivamente, eles não fazem.

\section{Referências}

Lefort, Claude (1972). Le Travail de l'auvre, Machiavel, Paris: Gallimard.

Lefort, Claude (1978). Les Formes de l'histoire, Paris: Gallimard.

Lefort, Claude (1981). L'Invention démocratique. Les Limites de la domination totalitaire, Paris: Fayard.

Merleau-Ponty, Maurice (1955). Les Aventures de la dialectique, Paris : Gallimard.

Merleau-Ponty, Maurice (1960). Signes, Paris: Gallimard. 